\title{
Direct Anterior Approach in THA without a fracture table in cases with associated adduction contractures of hip - an evaluation
}

\author{
Saran $\mathbf{R}^{1}$, Mishra $\mathbf{R}^{2}$ \\ ${ }^{1}$ Dr Rajat Saran, Associate Professor, Department of Orthopaedics, Chirayu Medical College and Hospitals, Bhopal, MP, \\ India, ${ }^{2}$ Dr Rakesh Mishra, L N Medical College, Bhopal, MP, India.
}

Address for correspondence: Dr Rajat Saran, Email: saran.rajat@gmail.com

\begin{abstract}
Introduction: The prerequisites of an optimal approach for total hip arthroplasty include a relatively short skin incision, easy accessibility to the acetabulum and proximal part of the femur, minimal damage to muscle bundles with minimal blood loss \& neuronal injury. Direct anterior approach of hip arthroplasty fulfils most of the criteria's. The aim of this prospective study is to evaluate the functional outcome of the patient, assess the utility and convenience of the direct anterior approach to the hip in a supine position on a standard radiolucent operation table, obviating the need of a fracture table and its complications, in cases of hip joint pathologies necessitating a total hip arthroplasty especially those associated with other conditions like adductor contractures, where both the deformities demand to be dealt with at the same sitting. Methods: This study comprises of total hip arthroplasties performed on sixteen hips in eleven patients between October 2011 to May 2014 at tertiary care teaching hospital. Indications in nine patients were idiopathic avascular necrosis, one had a non union of fracture femoral neck and one fracture trochanter with secondary osteoarthritis. Results: All the patients had an uneventful recovery. There was a significant improvement in the symptoms of all the patients. They were pain free. The limb length discrepancy was corrected in all except one patient who had a lengthening of the operated leg by two millimetres. Conclusion: It proves to be convenient with rewarding results in a rapid functional outcome. It does have a significant learning curve
\end{abstract}

Key words: Total hip arthroplasty, Adductor spasm, Direct anterior approach, standard radiolucent operating table.

\section{Introduction}

Carl Heuter, a German surgeon, was the first to describe the anterior approach to the hip as used today, in his classic work Der Grundriss der Chirurgie, published in 1881 [1,2]. Marius N Smith-Petersen [1886-1953], a Norwegian born American surgeon spread the anterior approach throughout the English speaking world so much so that today it is commonly referred to as the "SmithPetersen approach" [3]. In his Moynihan lecture in 1947 [4], he recounted his original planning and execution of the anterior approach to the hip joint. Other authors in their study successfully took advantage of the anterior approach in their osteotomies [5-7]. Fahey et al described a modified anterior approach [8]. He used the interval between tensor fasciae latae and Sartorius and transacted the tensor at the lower border of the incision. Beaule and colleagues have described using the anterior

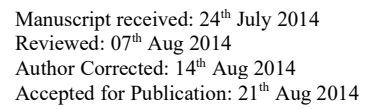

approach for the treatment of acetabular fractures with a total hip arthroplasty [9].

The evolution of the anterior approach started with Smith Petersen using the Heuter interval for treating terminal arthritis of the hip with vitallium mould arthroplasty after trying several materials like glass, Pyrex, Bakelite etc. His rationale for using this approach was that since extensive dissection normally involved in hip arthroplasty can be performed along structural planes, it is not destructive [10]. Judets \& colleague used this approach for hip arthroplasty in 1950 and described that to obtain good movement later we believe that it is essential to avoid all damage to muscle and bone [11]. We therefore use Heuter's vertical incision, which extends about $15 \mathrm{cms}$ down from the ASIS, passes between TFL and Sartorius, then lateral to rectus femoris and down to the capsule [11]. In 1955 O'Brien described that .Heuter's anterior straight incision does not require 
muscle cutting or detachment, and no post operative immobilization is needed"[12].

Luck [13] described difficulty in placing the prosthesis with Heuter's approach whereas Charnley [14] reported great success with his transtrochanteric approach. This declined the use of the anterior approach for many years. Surgeons using the anterior approach for THA being performed on a conventional operating table usually experience an increased difficulty in exposing and preparing the femoral canal for insertion of the femoral component. Using the figure of four position to externally rotate the hip during total hip arthroplasty or hemiarthroplasty, places the proximal end of the femur at a lower level as compared to the distal end which is elevated and as a result a proper exposure of the femoral canal is often inconvenient. A possibility of a varus or an anteroposterior placement of the implant, or in extreme cases a perforation of the cortex during broaching due to its malpositioning may be encountered [1]. These problems may be aggravated in obese patients. Judets [15] renewed interest in hip arthroplasty by the anterior approach with the help of an orthopaedic table which provides indirect traction to both lower limbs and combined with external rotation and hyperextension helps to dislocate the joint easily. This has gained popularity as suggested by the reports of Siguier and colleagues [16] and Matta and colleagues [17] especially with the use of minimally invasive hip arthroplasty. This table facilitates in hyperextension of the hip which props up the proximal end of the femur and along with some soft tissue releases like releasing the posterior capsule and if needed the piriformis muscle, brings the entry point of the femoral canal into a convenient elevated position to introduce the box punch giving a straight access to the canal. However, there have been reports of certain complications specific to the fracture table like ankle fractures and knee sprains $[16,17,18]$.
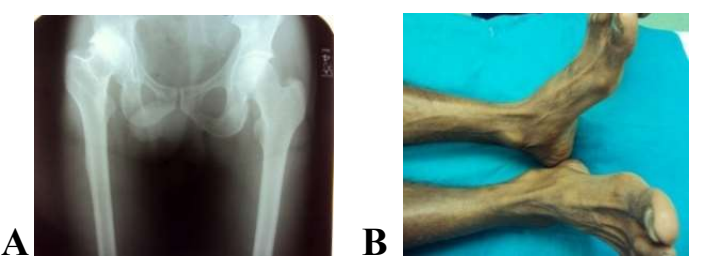

Fig 1: AVN left hip[A], shortening of [B],
In this study a direct anterior approach was used to perform total hip arthroplasties along with release of the coexisting adductor contracture in three cases at the same sitting, with the patient supine on a conventional operating radiolucent table which can be broken at the level of the pelvis to hyperextend the hips obviating the use of an orthopaedic table.

\section{Material and Methods}

This study comprises of total hip arthroplasties performed on sixteen hips in eleven patients between October 2011 to May 2014. The indication in nine patients was idiopathic avascular necrosis, one had a non union of fracture femoral neck and one fracture trochanter with secondary osteoarthritis. The minimum time interval between the two hips in bilateral cases was two weeks. The longest follow up has been of thirty one months and the shortest of ten weeks. Five patients had a bilateral involvement out of which three were females and two were males. In six patients, two females and four males, unilateral hips were involved. Three males having unilateral involvement also had an associated adductor contracture of the same hip with minimal internal rotation of the ipsilateral limb. These contractures were released at the same sitting. The ages of the patients ranged from 37 years to 55 years, the average age being 45.36 years. The types of implants were chosen on the basis of indications, availability and affordability.

A standard conventional radiolucent operating table was used in all cases, which could be broken at the level of the pelvis to hyperextend both hips. The patient was placed supine with the operated leg being draped free. The supine position helped to stabilize the pelvis and allowed easy measurement of leg length. Adductor tenotomy with obturator neurectomy preceded the total hip arthroplasty at the same sitting in three cases who had adductor spasm.

All the patients were given epidural anaesthesia except one who was subjected to general anaesthesia. The incision for THA was placed from a point $2.5 \mathrm{cms}$. lateral and distal to the anterior superior iliac spine and prolonged distally and slightly laterally along the longitudinal axis of Tensor fascia lata for 8 to $10 \mathrm{cms}$. 

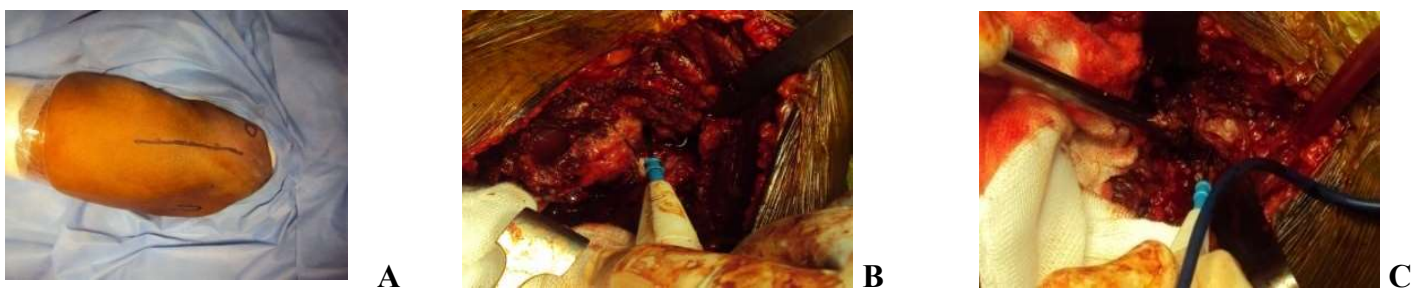

Fig 2: Skin incision [A], Ligation \&cauterization of lateral circumflex artery and its branches [B], resection of supracapsular fat pad $[\mathrm{C}]$

The bleeders in the subcutaneous tissue were cauterized and the fascial layer of TFL was exposed and incised in the middle of the length of TFL and a sub fascial dissection was done distally and proximally. Elevating the medial part of this fascia led to a fatty layer defining the Smith Peterson interval. A curved retractor was placed medial to TFL and Gluteus medius proximally and a finger dissection completely separated the fibres of Sartorius and TFL. Another retractor was placed distally near the greater trochanter and Sartorius and Rectus femoris muscles were retracted medially exposing the lateral aspect of the hip. This is an internervus and an intermuscular plane.

The lateral circumflex artery and its branches were identified and ligated [Fig 2]. The fascia between Rectus, TFL and capsule was dissected to reveal vastus lateralis and the precapsular fat was removed after electrocoagulation. The fascia below the rectus was further released and the rectus and Sartorius were further pulled medially exposing the proximal neck and the acetabular margins. A retractor was placed over the superior border of the neck and one below the inferior border. The anterior capsule was now incised along the intertrochanteric line and the anterosuperior border from distal to as proximal as possible [Fig 3]. The retractors were now placed within the cut capsule superiorly and inferiorly, basically three releases were done to adequately expose the neck and the acetabulum.

a. The medial release along the inferior border of the neck which could be extended upto the lesser trochanter.

b. The superior release along the superior border of the neck which can eztend upto the piriformis fossa.

c. The acetabular release between the proximal capsule and the labrum.

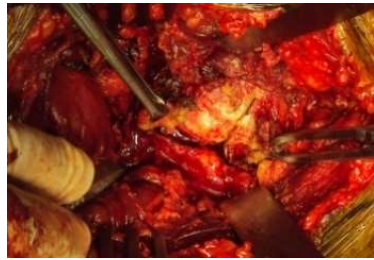

Fig 3: Incising the capsule

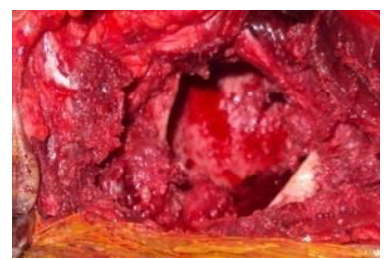

Fig.4: Cut femoral neck

A double osteotomy of the neck was performed in six cases without dislocating the hip and the cut disc of bone was removed [Fig 4]. The head was then removed with a corkscrew driver after removing the anterior osteophytes, whereas the head was first dislocated in the rest of the cases and then the neck was osteotomized.

Preparation of the acetabulum included removing the labrum and osteophytes from the margins. Adequate exposure of the acetabulum was achieved by placing at least three retractors one anteriorly, one posterolaterally and a medial one placed in the region of the transverse ligament, medial and inferior to the acetabulum. The acetabulum was reamed to the correct size by standard reamers. After the trial the correct sized cup was placed in the correct inclination and orientation with the help of a standard impactor. When used, locking screws were placed in position with flexible drills and screw drivers [Fig 5].

[A]

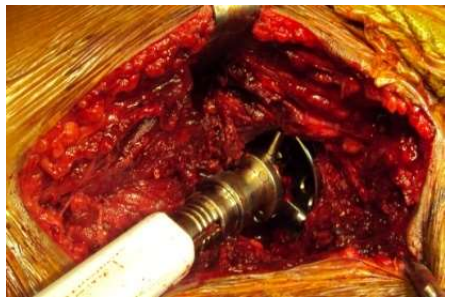

Fig 5: Reaming the acetabulum $[\mathrm{A}]$,

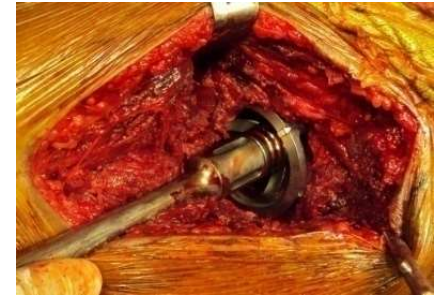

Trial cup [B]

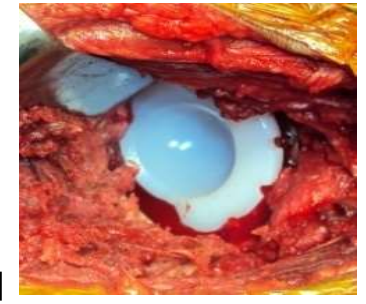

Final cup in position[C] 
Research Article

The table was broken at the level of the pelvis and the hip was hyperextended. This position popped the proximal femur into the operative wound.For the femoral preparation the operated leg was placed in hyperextension, adduction and complete external rotation. The opposite leg was abducted as much as possible Fig 6].

[A]

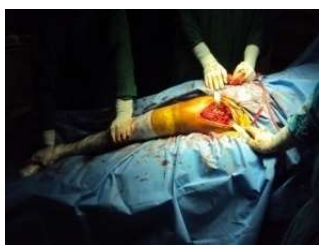

[B]

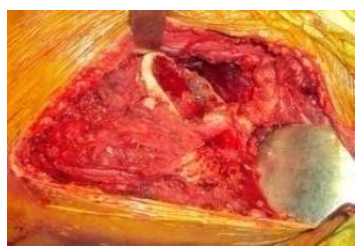

Fig 6: The operating table is bent at the level of the pelvis to hyperextend the hips [A], The trochanteric region is popped into the wound for easier preparation [B].

[A]

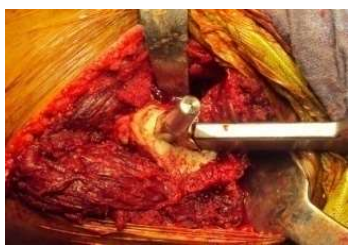

[B

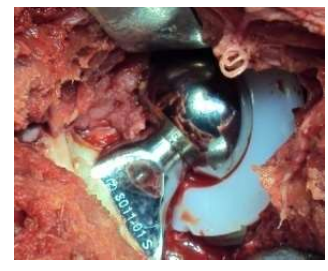

Fig 7: The femoral component cemented in position [A]. Final implants after reduction [B]

A retractor was placed inside the lateral capsular flap and a double pronged retractor was placed behind the trochanter but infront of gluteus medius. The posterior capsular fat pad was released hyperextension was achieved by breaking the table by 40 to 45 degrees, which allowed the trochanter to pop up into the operative wound. All muscles were pushed back and a retractor was placed in the calcar proximal to iliopsoas and the muscles were pushed medially. A bone hook placed in the canal brought the trochanter upward and laterally well in front of the acetabulum. We never needed to excise the piriformis. A standard broach was used for the canal. Initially the smallest size broach was used. A trial reduction was done and viewed on the image intensifier. The limb lengths were assessed and the size of the final components ascertained..The final femoral component was inserted by hand and impacted with the standard impactor angled at 45 degrees [Fig 7]. The wound was closed in layers with suction drains and dressed. Care was taken not to place the sutures too medially to avoid damage to the lateral femoral cutaneus nerve.

Post operatively the patients were encouraged to sit on the following day after surgery and made to stand without support on the second day after removal of the drain. Full weight bearing was started on the third or fourth postoperative day. None of the patients complained of severe pain postoperatively except for mild discomfort. Gentle exercises of the hip were instituted from the second postoperative day. The stitches were removed on the twelfth day. Those hips which had an adductor release were kept abducted for a minimum period of six weeks from day one.

\section{Results}

All the patients had an uneventful recovery. There was a significant improvement in the symptoms of all the patients. They were pain free. The limb length discrepancy was corrected in all except one patient who had a lengthening of the operated leg by two millimetres. This was corrected by a compensatory heel raise in the non affected limb. None of the patients complained of an abductor insufficiency.

[A]

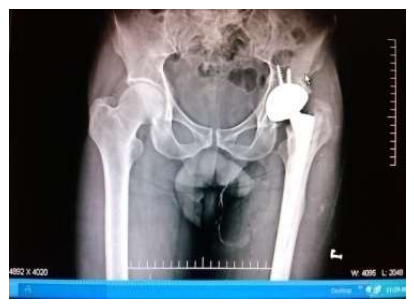

Fig 8: Post op skiagrm [A]
[B]

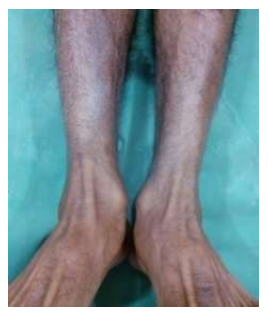

Limb length \& internal rotation corrected.[B] 
One patient however had a tingling sensation in the front of the ipsilateral thigh which gradually subsided after a period of approximately fourteen months. The functional outcome was assessed by Harris hip scores and was rated as excellent in one, good in nine and average in one patient who developed late onset infection and had to be given a thorough open surgical wash. The infection however subsided after twelve weeks.

\section{Discussion}

\section{Direct anterior approach [DAA]}

Alleviation of pain, a quick recovery of the limb function, safety and the ease to perform a procedure spells the success of any arthroplasty [19,20,21].

Direct anterior approach [DAA] to the hip is a form of a minimally invasive surgery [MIS] with a single incision. MIS was conceptualized by Watanabe in 1970s [22] and is defined as a surgical technique performed through a short skin incision to minimize injury to muscles or bones. The term minimally invasive does not necessarily indicate a short scar but rather refers to minimal damage to soft tissues, particularly muscles and their insertions.[23,24,25,26] Any injury to a muscle or its insertion is usually associated with decreased muscle strength and impaired proprioception.

The term 'direct anterior'actually referred to the part of the approach in the area of the hip itself. It uses an internervous plane. In this technique the capsule is approached through an interval between muscles supplied by the superior gluteal nerve [tensor fascia lata and gluteus medius] and those supplied by the femoral nerve [rectus femoris and sartotius, [26,29,32,33,34] without erasing or resecting any muscle causing no injury to them. Apart from these, it provides manifold benefits such as reducing intra operative blood loss, reducing perioperative pain, resulting in faster recovery, shortening hospital stay, and providing better external cosmesis.[19,21,23,27,28,29,30,34]

Cases with adductor contractures had to be released on the same sitting as the arthroplasty, because releasing them before an arthroplasty would not be convenient to place the limb in abduction due to the pain of arthritis in the ipsilateral hip whereas releasing them after the arthroplasty would not have allowed movements in the operated hip due to the contracture. Hence it was desirable to operate the patient in the same sitting in a convenient supine position which would provide access to the hip as well as the adductor region.

A supine position in THA poses increased difficulty in the exposure of the proximal femur for preparing the trochanteric region and gaining access to the femoral canal which is highly technique dependent. This occasionally leads to incorrect implant positioning.
Special operative fracture tables described by Matta and colleagues [17] have been used to overcome this difficulty in the anterior approach for THA. The possibilities of potential disadvantages like injuries to areas other than the hip region like occasional fractures of the ankle as the foot is required to be fixed in a foot holder or a pudendal nerve palsy due to the prolonged traction on the traction table, difficulty in checking range of motion, stability and cost of the table led us to use the conventional radiolucent operating table for DAA in THA in this study[17].

All the cases were done on a conventional radiolucent operating table and the patient was placed supine with the sympysis pubis directly at the level of the table break which acts as a fulcrum so that the hip could be easily extended to approx. 40-50 degrees and the trochanteric region could pop up into the operative wound after release of the posterior capsule for the preparation of femoral canal and proper positioning of the implant, the distal femur acting as a lever.

The advantages of the Direct anterior approach may be summarized as follows:

Soft tissue trauma and perioperative pain is minimal, healing is faster with a short incision cosmesis, post operative mobilization is rapid and rehabilitation is better and faster. The main advantage of this approach however is keeping the gluteal muscles intact, avoiding abductor and gluteal insufficiency.

However care should be exercised to avoid injury to the lateral femoral cutaneous nerve by keeping the incision as far laterally as possible on the thigh. Post operative dislocations are usually anterior but very rare. Dislocations reported by Siguier and colleagues [33], Matta and colleagues,[17] Kennon and colleagues [29] and Sariali and colleagues [18] were $0.96 \%$ in 1037 cases, $0.61 \%$ in 437 hips, $1.3 \%$ in 2132 hips and $1.5 \%$ in 1347 hips respectively. Ligation of the lateral circumflex artery and its branches with meticulous haemostasis in the superficial fatty layer greatly reduces blood loss and chances of post operative haematoma. Over enthusiastic use of retractors may damage the skin and musculature. Kennon and colleagues reported a deep vein thrombosis rate of only $0.8 \%$. Heterotopic ossification secondary o retraction has been rarely reported. 


\section{Conclusion}

We can conclude that performing total hip arthroplasties on hips, especially which are associated with deformities like adduction contractures and demand to be done at the same sitting can be conveniently performed on a standard radiolucent operating table in the supine position by bending it at the level of the pelvis to hyperextend the hip for easy exposure and access to the trochanteric region, obviating the inconvenience and complications of a fracture table, by the direct anterior approach. It proves to be convenient with rewarding results in a rapid functional outcome. It does have a significant learning curve.

Abbreviations: ASIS $=$ Anterior superior iliac spine, $\mathrm{TFL}=$ Tensor fascia lata, $\mathrm{THA}=$ Total hip arthroplasty, $\mathrm{AVN}=$ Avascular Necrosis, $\mathrm{DAA}=$ Direct anterior approach, MIS= Minimally invasive surgery.

\section{Funding: Nil}

\section{Conflict of interest: Nil}

\section{Permission from IRB: Yes}

\section{References}

1. Heuter C. Funfte abtheilung die verletzung und krankheithen des huftgelenkes, neunundzwanzigstes capitel. In: Heuter C, editor Grundriss der chirurgie. $2^{\text {nd }}$ edition. Leipzig: FCW Vogel: 1883. p. 129-200.

2. Vulpius O, Stoffel A. Operationen am huftgelenk, 2. Orthopadische resektionen und mobilisierung des huftgelenkes, 2. Vorderer hautschnitt nach Heuter. In: Vulpius O, Stoffel A. editors. Orthopadische Operationslehre. $3^{\text {rd }}$ edition. Stuttgart: Ferdinand Enke; 1924. p. 435-6.

3. Calandruccio R. Voies d'abord de la hanche. Milano, Barcelona, Bonn. In: Roy-Camille R, Laurin CA, Riley LH. editors, Membre inferieur, Alas de Chirugie orthopedique, vol. 3. Paris: Masson; 1991 p. 65-70.

4. W.A.L. IN MEMORIUM Dr. MN Smith-Petersen. J Bone Joint Srg Br 1953;35:482-4.

5. Salter RB. Innominate osteotomy in the treatment of congenital dislocation and subluxation of the hip. J Bone Joint Surg Br 1961.;43:518-39.

6. Pemberton PA. Pericapsular osteotomy of the ilium for treatment of congenital subluxation and dislocation of the hip. J Bone Joint Surg Am 1965;47:65-86.
7. Ganz R, Klaue K, Vinh TS, et al. A new periacetabular osteotomy for the treatment of hip dysplasias. Technique and preliminary results. Clin Orthop Relat Res 1988;232:26-36.

8. Fahey JJ. Surgical approaches to bone and joints. Surg Clin North Am 1949;29:65.

9. Beaule PE, Griffin DB, Matta JJ. The Levine anterior approach for total hip replacement as the treatment for an acute acetabular fracture. J Orthop Trauma 2004;18[9]:623-9.

10. Smith Petersen MN Approach to and exposure of the hip joint for mold arthroplasty J Bone Joint Surg Am 1949;31:40-6.

11. Judet J. Judet R. Use of an artificial femoral head for arthroplasty of the hip joint. J Bone Joint Surg Br 1950. 32-B 166-73.

12. O'Brien RM The technic for insertion of femoral head prosthesis by the straight anterior or heuter approach. Clin Orthop 1955;6:22-6.

13. Luck JV An approach for hip reconstruction. Broad visualization without osteotomy of the greater trochanter. Clin Orthop Relat Res 1973;91:70-85.

14. Charnley J. Low friction arthroplasty of the hip. Theory and Practice. London; Springer;1979.

15. Judet J. Judet H. Voie d'abord anterieure dans l'arthroplastie totale de la hanche. Presse ,Med 1985;14:1031-33.

16. Siguier T. Siguier M, Brumpt B. Mini incision anterior approach does not increase dislocation rate: a study of 1037 total hip replacements. Clin Orthop Relat Res 2004;426: 164-73.

17. Matta JM, Shahrdar C, Ferguson T. Single incision anterior approach for total hip arthroplasty on an orthopaedic table. Clin Orthop RelatRes 2005;441:11524.

18. Sariali E, Leonard P,Mamoudy P. Dislocation after total hip arthroplasty using Heuter anterior approach. J Arthroplasty 2008;23:266-72.

19. Chimento GF, Pavone V,Sharrock N, et al. Minimally invasive total hip arthroplasty: a prospective randomized study. J Arthroplasty 2005;20[2]:139-44.

20. Pour AE, Parvizi J, Sharkey PF, et al. Minimally invasive hip arthroplasty: what role does patient 
preco \nditioning play? J Bone Joint Surg Am 2007;89[9] 1920-7.

21. Mow CS, Woolson ST, Ngarmucos SG, et al. Comparison of scars from total hip replacements done with a standard or a mini incision. Clin Orthop Relat Res 2005;441:80-5.

22. Watanabe M . Arthroscopy: the present state. Orthop Clin North Am 1979;10[3]:505-22.

23. Berger RA, Jacobs JJ, Meneghini RM, et al.Rapid rehabilitation and recovery with minimally invasive total hip arthroplasty. Clin Orthop Relat Res 2004;429:23947.

24. Waldman BJ. Advancements in minimally invasive total hip arthroplasty. Orthopaedics 2003.26[ Suppl]:s833-6.

25. Sculco TP, Minimally invasive Totoal hip arthroplastyin the affirmative. J Arthroplasty 2004;19 [4 Suppl 1 ]78-80.

26. Wojceichowsky P, Kusz D, Kopec K,et al. Minimally invasive approaches in total hip arthroplasty. Ortop Traumatol Rehabil 2007;9[!]:1-7.

27. WrightJM, Crockett HC, Delgado S, et al. Miniincision for total hip arthroplasty a prospective, controlled investigation with 5-year follow up evaluation. J Arthroplasty 2004;19[5]:538-45.
28. Kennon R, Keggi J, Zatorski LE, etal. Anterior approach for total hip arthroplasty: beyond the minimally invasive technique. J Bone Joint Surg Am 2004; 86A[Suppl]:291-7.

29. Kennon RE, Keggi JM, Wetmore RS, et al. Totoal hip arthroplasty through a minimally invasive anterior surgical approach. J Bone Joint Surg Am2003; 85A[Suppl]:439-48.

30. Woolson ST, Mow CS, Syquiya JF, et al. Comparison of primary total hip replacements performed with a standard incision or a mini incision . J BONE Joint Surg Am 2004;86-A[7]:1353-8.

31. Sculco TP, Jordan LC. The mini-incision approach to total hip arthroplasty. Instr Course Lect. 2004;53:141-7.

32. HozacK WJ. Direct anterior approach for THA. Presented at the $75^{\text {th }}$ Annual AAOS Meeting,San Francisco, March 5-9,2008.

33. Siguier T, Siguier M, Brumpt B. Mini incision anterior approach does not increase dislocation rate: a study of 1037 total hip replacements. Clin Orthop Relat Res 2004;426:164-73.

34. Sculco TP, Jordan LC, Walter WL. Minimally invasive total hip arthroplasty: the hospital for Special Surgery experience. Ortho Clin North Am2004;35[2]:137-42.

\section{How to cite this article?}

Saran R, Mishra R. Direct Anterior Approach in THA without a fracture table in cases with associated adduction contractures of hip - an evaluation. Int J Med Res Rev 2014;2(5):450- 456. doi:10.17511/ijmrr.2014.i05.14 